\title{
Polymeric encapsulation of 1-2-3 ceramic superconductors
}

\author{
B CHAUDHURI, R M ANKLEKAR, C A THOMAS*, \\ T R RAMA MOHAN and OM PRAKASH*
}

*Materials Science Centre, Department of Metallurgical Engineering, Indian Institute of Technology, Bombay 400076 , India

\begin{abstract}
YBa}_{2} \mathrm{Cu}_{3} \mathrm{O}_{7-x}$ pellets have been found to degrade and lose superconducting properties when exposed to the normal atmosphere for long durations. Hence, coating the superconducting pellets with a polymer to protect it from moisture and $\mathrm{CO}_{2}$ of the ambient atmosphere is highly desirable. In this paper the criteria of selection of a polymer and some preliminary studies on polymeric encapsulation of 1-2-3 pellets are reported. Fevitite epoxy and stycast have been found to show encouraging results.
\end{abstract}

Keywords. $\mathrm{YBa}_{2} \mathrm{Cu}_{3} \mathrm{O}_{7-x}$; oxide superconductor; polymeric encapsulation; chemical stability; atmospheric degradation.

\section{Introduction}

High $T_{c}$ oxide superconductors (SC) in general and $\mathrm{YBa}_{2} \mathrm{Cu}_{3} \mathrm{O}_{7-x}(1-2-3)$ in particular have been found to be very susceptible to moisture and $\mathrm{CO}_{2}$ of the atmosphere when exposed for long durations. The reaction of 1-2-3 compound with moisture and $\mathrm{CO}_{2}$ leads to the precipitation of non-superconducting $\mathrm{Y}_{2} \mathrm{BaCuO}_{5}$, $\mathrm{BaCuO}_{2}, \mathrm{CuO}, \mathrm{Ba}(\mathrm{OH})_{2}$ and $\mathrm{BaCO}_{3}$ phases (Gallagher 1987; O'Bryan and Gallagher 1987) and a slight loss of lattice oxygen (Yan et al 1988). It has been observed that samples exposed to air at $\sim 85^{\circ} \mathrm{C}$ with $\sim 85^{\circ}$ relative humidity lost superconductivity and became mostly amorphous within the penetration depth $(\sim 10 \mu \mathrm{m})$ of X-rays (Yan et al 1988). Further a reduced oxygen content in $\mathrm{YBa}_{2} \mathrm{Cu}_{3} \mathrm{O}_{7-x}(x \geqslant 0.5)$ has shown no significant improvement in its chemical stability in an aqueous medium (Gallagher 1987). Therefore, hermetic encapsulation of SC samples by a compatible polymer not susceptible to moisture and $\mathrm{CO}_{2}$ is highly desirable. As $1-2-3$ material finds SC applications only at cryotemperatures as of liquid nitrogen, it is essential that the protective coatings are resistant to cryo-thermal cycling as well.

Polymeric encapsulation of electronic components and circuits for protection against atmospheric attack is a well-established practice and is widely used in semiconductor industry (Jowett 1971). However, except for a few references (Bayless 1987; Sato et al 1988; Vasquez et al 1989a, b), scarcely any literature exists on polymeric coatings of oxide SC ceramics. In this paper some of the preliminary experiments conducted on polymeric encapsulation of 1--2--3 oxide SC using various commercially available as well as laboratory formulations are reported.

The typical problems encountered during the process of polymeric encapsulation of oxide SC are: seeping in of polymeric/monomeric material through the pores of the bulk 1-2-3 material during the initial stages of curing and/or evolution of solvent vapours while curing, which get transported through the pores to the interior of the bulk SC material. Either of these processes deteriorate the SC properties of the material. A proper control of process parameters during encapsulation of SC pellets 
is therefore required to overcome the above problems. Experiments carried out in this respect and the results obtained are presented in this paper.

\section{Experimental}

The curing behaviour (rate of curing and curing time) for six different polymeric formulations (table 1) was studied by applying thin layers of $\sim 0.01-0.1 \mathrm{~mm}$ thickness depending on the polymer onto PTFE sheets and monitoring the weight changes at regular intervals of time. The extent to which the gases evolved during curing of the polymeric coating and that got trapped within the pores of 1-2--3 SC ceramic were estimated for different polymers by applying equal amounts by weight of polymer onto two PTFE sheets one with and the other without a pellet. The amount of entrapped gases was determined by comparing the weight loss in the two cases.

Chalking behaviour of different polymers was studied by keeping thin films of polyvinyl acetate and the above six formulations in air of $\sim 90 \%$ relative humidity and observing any change in physical appearance with time. The resistance to cryo-thermal cycling of thin polymeric films and coated pellets of varying thickness was evaluated by liquid nitrogen dip test up to 100 cryocycles (room temp.-liq $\mathrm{N}_{2}$ temp.-room temp.) and observing the polymer-substrate interface for microcracks. The coated pellets were subjected to cryocycling to study the effect of thermal mismatch between the polymers and the SC substrate.

TGA was carried out using Dupont 9900 thermal analyser to investigate the pick-up of moisture and $\mathrm{CO}_{2}$ from the ambient and the accompanying phase changes. XRD studies were carried out using Philips PW 1710 controller unit on freshly-annealed uncoated pellets, uncoated pellets left in ambient for one month and the polymer coated pellets exposed to air for the same period to study the extent of deterioration caused by the reaction with the ambient. The lattice oxygen content for the three different $1-2-3$ pellets was determined by iodometric titration.

\section{Results and discussion}

Figure 1 shows the curing behaviour at room temperature for six different polymeric formulations. Stycast was the only polymer which showed no appreciable weight change during curing. All the other polymeric formulations showed weight loss except

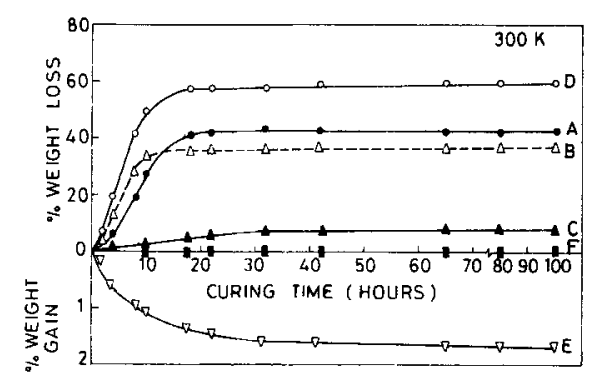

Figure 1. \% Weight change of various polymeric formulations as a function of curing duration. 
Table 1. Percentage of evolved gases entrapped within the 1-2-3 ceramic SC pellets (porosity $\sim 15 \%$ ) for different polymeric formulations.

\begin{tabular}{llc}
\hline $\begin{array}{l}\text { Polymer } \\
\text { code }\end{array}$ & Polymer name and source & $\begin{array}{c}\% \text { of evolved } \\
\text { gases entrapped }\end{array}$ \\
\hline A & Apcolite varnish (Asian Paints Ltd.) & 14.0 \\
B & Apcolite paint (Asian Paints Ltd.) & 6.2 \\
C & Polyurethene based Lab formulation & 8.4 \\
D & Nitrocellulose (D.J. Paints Ltd.) & 40.5 \\
E & Fevitite epoxy (Apuraj Chemicals) & $*$ \\
F & Stycast (Emerson \& Cumings Inc., USA) & $*$
\end{tabular}

* No gases evolved during curing

Table 2. Physical condition of various polymer coatings after different number of dips in liquid nitrogen from room temperature.

\begin{tabular}{lllllllll}
\hline $\begin{array}{l}\text { Polymer } \\
\text { code }\end{array}$ & $\begin{array}{c}\text { Polymer name } \\
\text { and source }\end{array}$ & \multicolumn{6}{c}{$\begin{array}{c}\text { Condition* of polymer coatings } \\
\text { after different number of dips }\end{array}$} \\
\hline A & $\begin{array}{l}\text { Apcolite varnish } \\
\text { (Asian Paints Ltd.) }\end{array}$ & 1 & 1 & 2 & 3 & 5 & - & - \\
B $\quad \begin{array}{l}\text { Apcolite paint } \\
\text { (Asian Paints Ltd.) }\end{array}$ & 1 & 1 & 2 & 3 & 4 & 5 & - \\
C $\quad \begin{array}{l}\text { Polyurethene based } \\
\text { Lab formulation }\end{array}$ & 3 & 4 & 5 & - & - & - & - \\
D & $\begin{array}{l}\text { Nitrocellulose } \\
\text { (D.J. Paints Ltd.) }\end{array}$ & 5 & - & - & - & - & - & - \\
E & $\begin{array}{l}\text { Fevitite epoxy } \\
\text { (Apuraj Chem. Ltd.) }\end{array}$ & 1 & 1 & 1 & 1 & 1 & 1 & 1 \\
F & $\begin{array}{l}\text { Stycast } \\
\text { (Emerson \& Cumings } \\
\text { Inc.. USA) }\end{array}$ & 1 & 1 & 1 & 1 & 1 & 1 & 1 \\
\hline
\end{tabular}

\footnotetext{
* Legend:

1- No cracks as seen under optical microscope (Mag. $200 \times$ )

2-Blister formation as seen under optical microscope (Mag. $200 \times$ )

3 --Fine cracks as seen under optical microscope (Mag. $200 \times$ )

4-Large cracks as seen under magnoscope (Mag. 15 $\times$ )

5-Complete embrittlement to pieces as observed by naked eye
}

fevitite cpoxy which showed weight gain of $\sim 2 \%$. The $\%$ weight change for all the polymeric formulations reached a plateau at $\sim 20 \mathrm{~h}$ of curing. The evolution and entrapment of gases during curing for six different polymeric formulations studied are tabulated in table 1. It is observed that fevitite epoxy and stycast give the best results as both these do not evolve any gases during curing. Some chalking was observed for polyvinyl acetate, nitrocellulose and apcolite paint films left in air at $\sim 90 \%$ relative humidity for long durations.

The room temperature to liquid nitrogen cryo-thermal cycling results for various polymeric coatings are tabulated in table 2 . It is observed that except for fevitite 

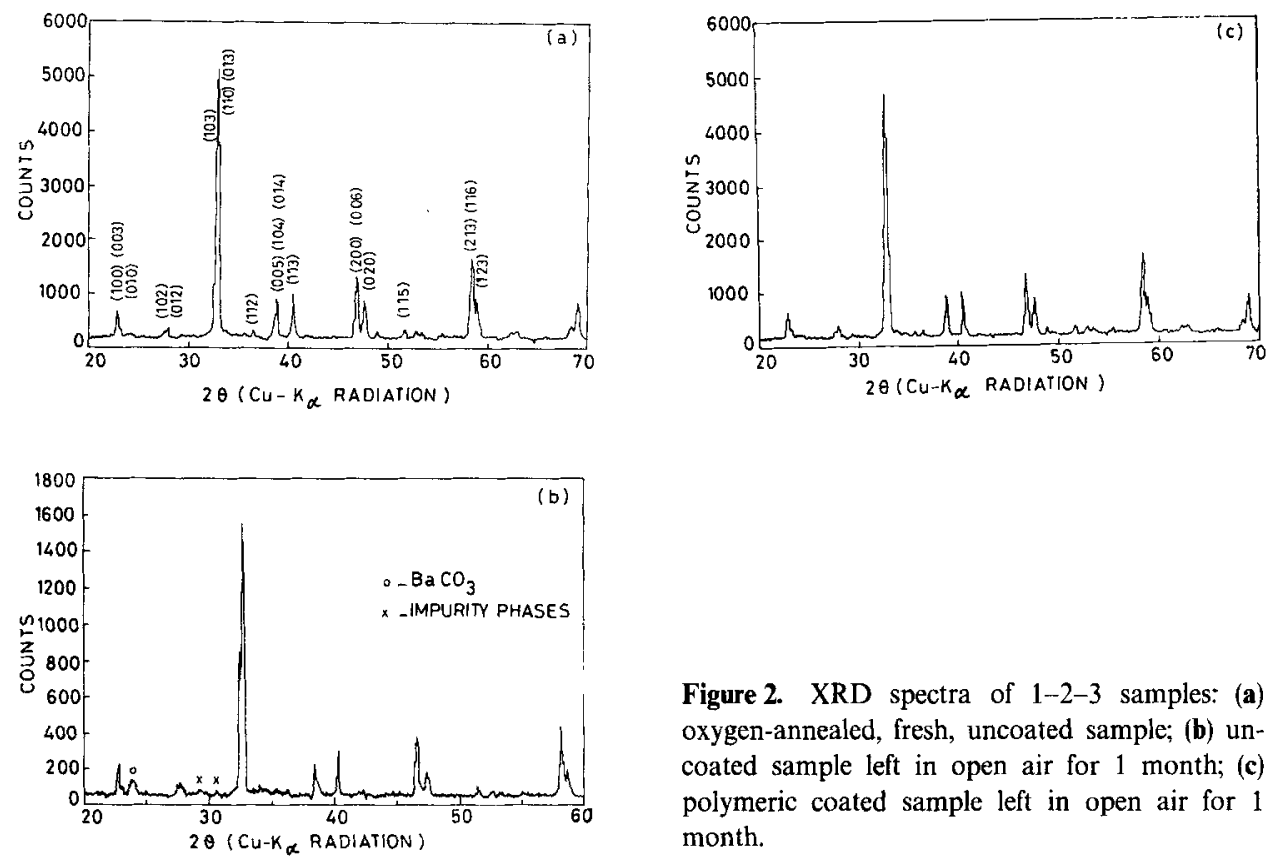

Figure 2. XRD spectra of 1-2-3 samples: (a) oxygen-annealed, fresh, uncoated sampic; (b) uncoated sample left in open air for 1 month; (c) polymeric coated sample left in open air for 1 month.

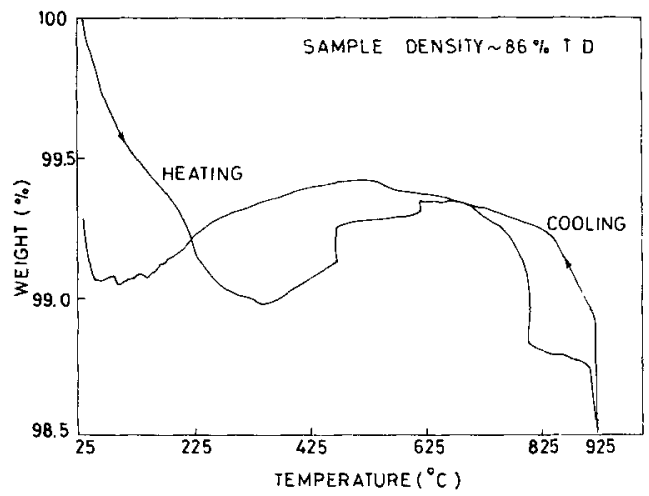

Figure 3. TGA curve of 1-2-3 sample left in open atmosphere having relative humidity $\sim 65 \%$ for 1 month.

epoxy and stycast, all the others developed microcracks within 30 cryocycles. The coatings became so fragile that even careful handling at liquid nitrogen temperature resulted in crumbling down to pieces. Considerable stresses develop at the interface of the bulk 1-2-3 material and the polymer due to relatively higher glass transition temperatures and thermal mismatch, resulting in the cracking of the coating. Only fevitite epoxy and stycast have been found to withstand 100 cryocycles without developing any microcracks. It was observed that thick coatings $\sim 0.1 \mathrm{~mm}$ were more adaptable to cryo-thermal cycling.

XRD analysis of freshly annealed uncoated pellets showed only the orthorhombic 1-2-3 phase (see figure 2a). XRD analysis carried out on uncoated pellets exposed to the open air for one month showed some traces of $\mathrm{BaCO}_{3}$ phase (see figure $2 \mathrm{~b}$ ). 
Figure 3 shows the TGA curve obtained for uncoated pellet exposed to air for one month. It is clear from the figure that $\sim 1 \%$ by weight of moisture and $\mathrm{CO}_{2}$ pick-up is registered by the $1-2-3$ pellets confirming the chemical instability of $1-2-3$ phase when exposed to atmosphere for long durations. Figure $2 \mathrm{c}$ shows the XRD spectra of coated 1-2-3 pellet exposed to air for one month. The spectra shows only the orthorhombic phase indicating that the polymeric encapsulation does provide protection against atmospheric attack. However, slight loss $(<2 \%)$ of lattice oxygen on prolonged exposure to the ambient has been observed for some of the coated pellets.

\section{Conclusions}

The problems associated with the polymeric encapsulation of ceramic superconductors have been identified. Porosity in the bulk SC material restricts the choice of the encapsulating material to those which evolve minimum amount of vapours during curing. Polyvinyl acetate, nitrocellulose and apcolite paint have been found to show some chalking behaviour. Stycast and fevitite epoxy have been found to perform the best as encapsulating materials for 1-2-3 pellets. Further work and ASTM(D) tests for adhesion, moisture permeation etc. need to be carried out in this direction.

\section{Acknowledgements}

The authors gratefully acknowledge Dr V K Misra, Director, DST for drawing our attention to a useful reference and his keen interest in the problem. Thanks are also due to Prof A G Rao for some experimental support.

\section{References}

Bayless R G 1987 Proc. Int. SAMPE Electron. Conf., Santa Clara (eds) N H Kordsmejer, C A Harper and S M Lee (Santa Clara: Covina SAMPE) 1147

Gallagher P K 1987 Adv. Ceram. Mater. 2632

Jowett C E 1971 in Materials in Electronics, Business Books London 1

O'Bryan H M and Gallagher P K 1987 Adv. Ceram. Mater. 2640

Sato K, Omae S, Kojima K, Hashimoto T and Koinuma H 1988 Jpn. J. Appl. Phys. 27 L2088

Yan M F, Ling H C, O'Bryan H M, Gallagher P K and Rhodes W W 1988 Mater. Sci. Eng. B1 119

Vasquez R P, Hunt B D and Foote M C 1989a Appl. Phys. Lett. 542373

Vasquez R P, Foote M C and Hunt B D 1989b Appl. Phys. Lett. 551801 